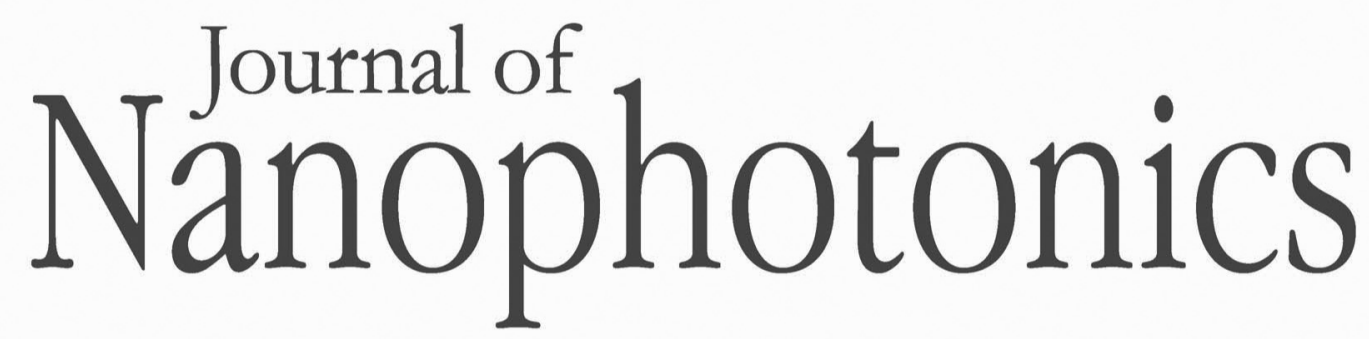

SPIEDigitalLibrary.org/jnp

\title{
Commentary: Photovoltaics firmly moving to the terawatt scale
}

José M. Martínez-Duart

Jorge Hernández-Moro

\section{O SPIE}




\title{
Commentary: Photovoltaics firmly moving to the terawatt scale
}

\author{
José M. Martínez-Duart and Jorge Hernández-Moro \\ Autónoma University of Madrid, Applied Physics Department (C-XII) and N. Cabrera Materials \\ Institute, Campus de Cantoblanco, E-28049 Madrid, Spain \\ martinez.duart@uam.es
}

Paper 13012CT received Mar. 5, 2013; accepted for publication Mar. 7, 2013; published online Mar. 22, 2013.

During the last two decades, the deployment of solar cells for the direct generation of electricity has been quite notable, and photovoltaic (PV) systems can at present be considered as a mature technology that is often incorporated in utilities portfolios. Of all sources of renewable energy, PV solar cells probably constitute the best example illustrating the technology-learning mechanism. The last decade has seen a real fall of prices of PV solar cells after the silicon shortages of the 2003 to 2006 period. Figure 1 shows in a log-log space the cost (in constant 2012

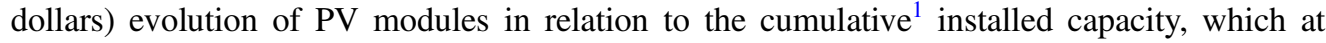
present is about $100 \mathrm{GW}$ in the whole world. ${ }^{1,2}$

This exceptional decrease in prices has been due to continuous improvements in solar-cell efficiency, advances in thin-film technologies, and enlargement of the markets (economies of scale). All of this has caused the actual solar-cell module prices to plunge under $\$ 1$ per peak watt, while some Chinese companies are announcing prices of about $\$ 0.50$ per peak watt for the year 2015. In spite of this great success, there is at present concern, especially among European and American companies, that the exponential growth shown by the cumulative installed power during the last decades cannot last for long. The European Photovoltaic Industry Association (EPIA) has stated: "Industry now (May 2012) finds itself through a weathering storm."3 Consequently, one of the main objectives of this commentary is to explain how these worries can be compatible with the great success in the deployment of PV installations in the recent past.

The PV industry is still predominantly based on crystalline silicon, but the share of the thinfilm second generation (2G) cells like those based on cadmium telluride is continuously increasing (now about $15 \%$ to $18 \%$ ), since they require much less materials, and make use of large-area deposition techniques and low-cost substrates. In addition, and in order to overcome the Shockley-Queisser limit ${ }^{4}$ for single-junction devices, there is a lot of research on third-generation (3G) solar cells. These cells often comprise semiconductor quantum dots or wells of different sizes, and consequently bandgaps, enabling the absorption of practically the whole solar spectrum. Another interesting type of $3 \mathrm{G}$ solar cells is based on the intermediate semiconductor bandgap concept, according to which the absorption of photons with energies lower than the bandgap is allowed by means of a two-step process. ${ }^{5}$

Trying to assess the future evolution of PV electricity, we focus our attention to both the predicted market-size evolution and the envisioned technological developments. Most reputed scenarios [International Energy Agency (IEA), EPIA, etc.] have piloted quite elaborate studies to forecast the amount of solar energy in the electricity mix until 2050. One of the most accepted scenarios related to the contribution of PV electricity is the BLUE Scenario, ${ }^{6}$ from the IEA, which predicts a value of PV installed cumulative power of $1.15 \mathrm{TW}$ in 2050 .

In order to better appreciate future-generation needs, we have plotted in Fig. 2 the values of the PV cumulative installed power $q(t)$ from the mid 1970s up to the end of 2012. ${ }^{1}$ Similar to the case of the learning curve, the representation of $q(t)$ can only be really appreciated if we use a log scale. We can observe from this figure that only since 1990, when the PV power generation was already well established, $q(t)$ has grown up by almost three orders of magnitude. In general, the growth rate has been so huge that, as can observed in the figure, the present installed power is $100 \mathrm{GW}$ and, after just one further order of magnitude, the $q(t)$ curve will have entered the terawatt (TW) scale, as predicted by the IEA BLUE Scenario for 2050. 


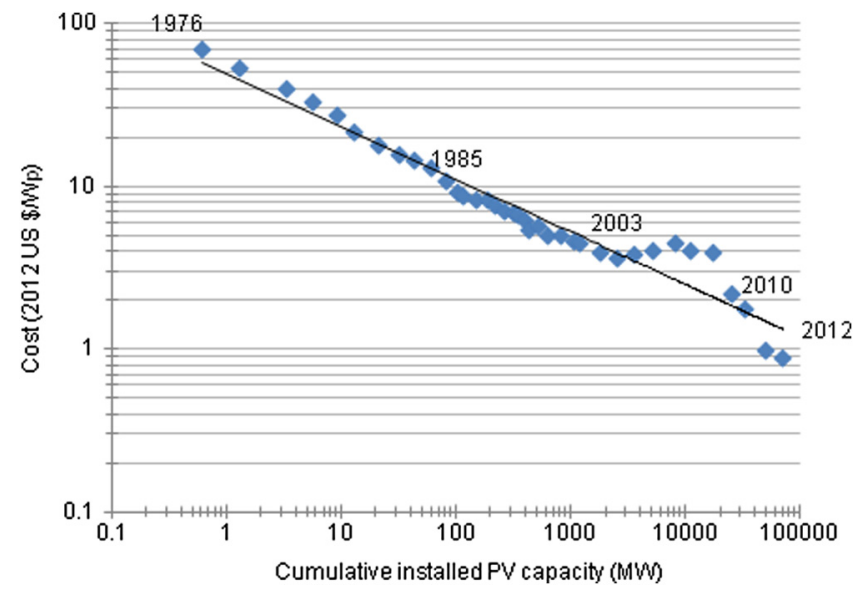

Fig. 1 Cost of PV modules between 1976 and 2012 as a function of cumulative installed PV capacity.

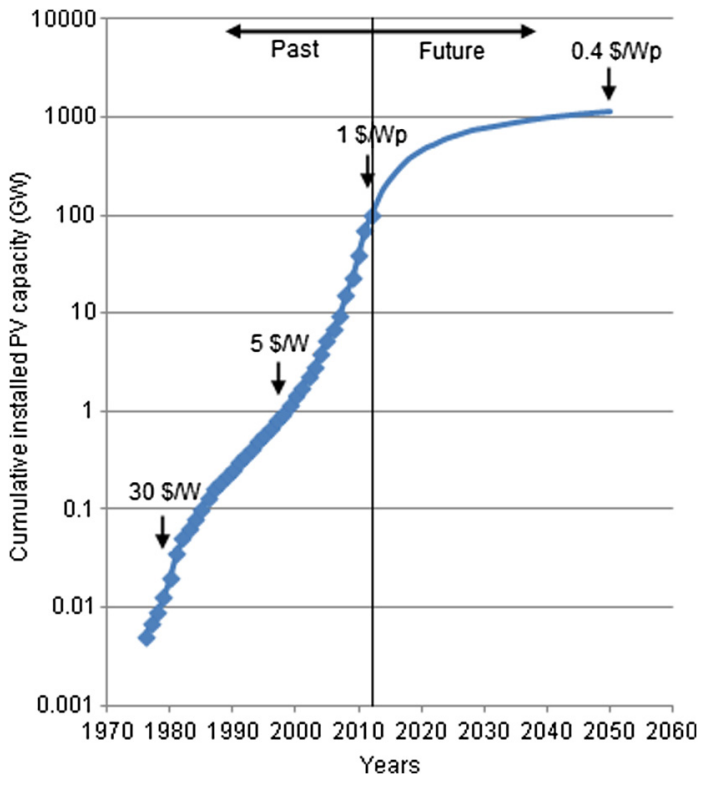

Fig. 2 Cumulative installed PV capacity for the period 1976 to 2012 and predicted values to 2050.

In Fig. 2, we have also sketched a tentative curve representing the possible $q(t)$ in the future. Evidently, since we are using a log scale, the line should approach the 2050 value of 1.15 TW with a very small slope because, otherwise, the amount of PV installed power would reach completely unrealistic values during the 2050 to 2060 decade. In addition, we also show in Fig. 2 a few marks indicating the cost, always in constant dollars, of the PV modules. The value for 2050 has been previously estimated by $\mathrm{us}^{1}$ as $\$ 0.40$ per peak watt.

After a simple calculation, one can conclude from Fig. 2 that from the 1970s, the continuous yearly growth rate has been around 30\%. However, from now until 2050 an annual growth rate of about $7 \%$ will suffice. If the growth rate would increase to $10 \%$, the value of $q(t)$ in 2050 would surpass the objective of the most optimistic IEA scenario. ${ }^{6}$ It is therefore concluded that the growth rate will slow down strongly in comparison to present values. This is what partially explains some of the actual musings of the European and American PV industries.

At this point, let us remark on some of the facts characteristic of the last decade concerning PV electricity. First, we observe that we have just reached the 100-GW mark, a value that no one could have predicted a decade earlier. Second, the installation of PV systems, which in the past was mainly concentrated in Europe, is at present markedly being extended to non-European 
countries: China, the United States, the Middle East, North Africa, etc. Therefore, the IEA BLUE scenario of moving to the terawatt scale in the next three to four decades seems very plausible. It even looks more realistic if one takes into account the predicted lowering of the PV levelized cost of energy for the 2012 to 2050 period, ${ }^{1,6}$ which will allow many regions of the world, with good solar resources, to reach grid parity within the next one or two decades. Evidently, in special locations like the Canary Islands, Hawaii, etc., where a high proportion of the electrical energy has to be imported, the grid parity could be attained even sooner.

Evidently, some precautions should be taken in order to make a smooth transition from the present $100-\mathrm{GW}$ to the TW scale. It is known that for medium-high penetration (20\% to $30 \%)$ of renewable energy-source in an electricity distribution system (20\% to 30\%), some integration techniques based upon several enabling technologies should be implemented. Therefore, in the near future there will be a large focus of R\&D activities related to energy storage (batteries, supercapacitors, hydrogen, etc.), smart grids, long-distance power transmission (HVDC), etc. An emerging concern is related to a possible shorter lifetime $\mathrm{T}$ of the less costly $2 \mathrm{G}$ thinfilm solar cells, which are continuously gaining a higher share of the PV market. This is because the levelized cost of PV electricity is very sensitive to T. ${ }^{1}$ Therefore, accelerated aging tests of PV modules will have to be developed to ensure that the lifetimes of $2 \mathrm{G}$ solar cells are comparable to those of crystalline-silicon ones (about 30 years).

From this commentary, it can be concluded that the IEA objectives of reaching a cumulative installed photovoltaic power of a few terawatts in 2050 can be achieved without the need of surmounting any significant barrier. It will only be necessary to maintain a continuous annual growth rate of about 10\%, much less than that of the last decade (about 40\%). Although intensive research should continue on $3 \mathrm{G}$ solar cells, we believe that the above objectives could also be reached based on the present scientific state-of-the-art ${ }^{7}$ characteristic of $1 \mathrm{G}$ and $2 \mathrm{G}$ solar cells, together with the expected future improvements derived from a profound knowledge of materials science and engineering.

\section{References}

1. J. Hernandez-Moro and J. M. Martinez-Duart, "Analytical model for solar PV and CSP electricity costs: present LCOE values and their future evolution," Renew. Sust. Energ. Rev. 20(1), 119-132 (2013), http://dx.doi.org/10.1016/j.rser.2012.11.082.

2. European Photovoltaic Industry Association (EPIA), "Highlight: World's solar photovoltaic capacity passes 100-gigawatt landmark after strong year," http://www.epia.org/news/news/ \#news-10 (February 2013).

3. European Photovoltaic Industry Association (EPIA), "Global Market Outlook for Photovoltaics Until 2016," http://www.epia.org/fileadmin/user_upload/Publications/GlobalMarket-Outlook-2016.pdf (May 2012).

4. W. Shockley and H.J. Queisser, "Detailed balance limit of efficiency of p-n junction solar cells," J. Appl. Phys. 32(3), 510 (1961), http://dx.doi.org/10.1063/1.1736034.

5. E. Garcia-Hemme et al., "Sub-bandgap spectral photo-response analysis of Ti supersaturated Si," Appl. Phys. Lett. 101(19), 192101 (2012), http://dx.doi.org/10.1063/1.4766171.

6. International Energy Agency (IEA), "Technology Roadmap-Solar Photovoltaic Energy," International Energy Agency IEA/OEDC, Paris, pp. 1-40, http://www.iea.org/ publications/freepublications/publication/pv_roadmap.pdf (2010).

7. R. Singh, "Why silicon is and will remain the dominant PV material," J. Nanophoton. 3(1), 032503 (2009), http://dx.doi.org/10.1117/1.3196882. 